\title{
GIL SÁNCHEZ MUÑOZ (1370-1447), EL ANTIPAPA CLEMENTE VIII. DOCUMENTACIÓN INÉDITA DE LOS ARCHIVOS DE TERUEL ${ }^{1}$
}

\author{
Germán Navarro Espinach \\ Concepción Villanueva Morte \\ UNIVERSIDAD DE ZARAGOZA
}

Resumen: Gil Sánchez Muñoz constituye un personaje histórico extraordinario dentro de las elites económicas de la Corona de Aragón por la multiplicidad de cargos y funciones que copó desde fines del siglo XIV hasta mediados del siglo XV. En estas líneas se analiza minuciosamente sus estrategias y formación social, su carrera eclesiástica, su papel en el pontificado en Peñíscola y obispado de Mallorca. Como colofón se publica una documentación inédita, memorial de bienes y donación de reliquias de este individuo.

Palabras clave: Gil Sánchez Muñoz, Teruel, Pontificado de Peñíscola, Obispado de Mallorca, siglos XIV- XV.

\begin{abstract}
Gil Sánchez Muñoz constitutes an extraordinary historical figure inside the economic elites of the Crown of Aragón because of the multiplicity of posts and functions he dominates from the end of the XIV century until the mid XV century. In these lines they are analysed in depth his strategies and social formation, his ecclesiastical career, his rol in the pontificate of Peñíscola and the bishopric of Mallorca. Finally it is disclosed unpublished documentation, goods' memorial and donation of relics of this figure.
\end{abstract}

Keywords: Gil Sánchez Muñoz, Teruel, Pontificate of Peñíscola, Bishopric of Mallorca, XIV-XV centuries.

\footnotetext{
1. El presente estudio se integra en el proyecto de investigación interuniversitario Migraciones, élites económicas e identidades culturales en la Corona de Aragón (1350-1500), dirigido por el profesor Paulino Iradiel y subvencionado por el Ministerio de Educación y Ciencia durante 2006-2008 (referencia HUM2005-04804/HIST).
} 


\section{LA BIOGRAFÍA DE UNA PERSONA ES LA HISTORIA DE SU FAMILIA}

Hace cuatro años publicamos un avance de las nuevas investigaciones que venimos realizando sobre el linaje noble de los Sánchez Muñoz y otras familias en la ciudad de Teruel durante el siglo $\mathrm{XV}^{2}$. Como efecto de este trabajo, la Real Academia de la Historia nos propuso la realización de varias voces sobre miembros del citado linaje aragonés para el Diccionario Biográfico Español, entre los cuales destacaba el clérigo Gil Sánchez Muñoz y Carbón, más conocido como el antipapa Clemente VIII, sucesor de Benedicto XIII, el papa Luna ${ }^{3}$. Sin duda, se trata de un personaje con una trayectoria muy atractiva por haber estado vinculado a la historia de los cuatro países principales de la Corona de Aragón en el tránsito del siglo XIV al XV: nacido en Teruel, arcipreste de Santa María en dicha ciudad, chantre de la catedral de Gerona, canónigo de la sede valenciana, pontífice en el castillo de Peñíscola y, tras su renuncia, obispo de Mallorca, entre otros cargos y destinos. Para quienes estudiamos el mundo de la movilidad geográfica de las elites económicas con vistas al análisis de los procesos de formación de identidades culturales, él y su familia suponen un observatorio sociológico de primera magnitud. Además, el conocimiento cada vez mayor que poseemos de los archivos turolenses y valencianos al respecto converge con las iniciativas citadas al principio en la necesidad de divulgar documentación inédita encontrada sobre este personaje y su contexto familiar ${ }^{4}$. Vale la pena hacerlo sobre todo teniendo en cuenta que han pasado treinta años sin que se haya dedicado ningún estudio monográfico nuevo sobre la historia particular del papa turolense.

La primera reseña biográfica documentada que conocemos la realizó a principios del siglo pasado un descendiente suyo, el barón de la Linde 5 . Haciéndose eco de que su figura histórica no había sido tratada con aquella consideración y justicia que merecía, fray Manuel García Miralles publicó en la revista de la Diputación de Teruel del año 1954 un estudio basado sobre todo en documentos del archivo de la catedral de Valencia ${ }^{6}$. Veintidós años después, un erudito local

2. Navarro Espinach, G., «Muñoces, Marcillas y otras familias dominantes en la ciudad de Teruel (14351500)», en Anuario de Estudios Medievales, 32/1 (2002), pp. 723-775.

3. Navarro Espinach, G., «Sánchez Muñoz y Carbón, Gil», en Diccionario Biográfico Español, Madrid, Real Academia de la Historia, en prensa.

4. Villanueva Morte, C., Movilidad social y relaciones económicas entre los reinos de Aragón y Valencia en el siglo $X V$, Tesis Doctoral inédita en la modalidad de Doctorado Europeo, 4 vols., Universidad de Zaragoza, curso 2005-2006, dirigida por G. Navarro Espinach.

5. BARÓN de LA Linde, «Don Gil Sánchez-Muñoz y Carbón. Antipapa Clemente VIII», en su obra Noticia histórico-genealógica de la familia Sánchez-Muñoz de Teruel, señores de Finojosa, barones de la villa y castillo de Escriche y de la Linde, Valencia, Tipografía Moderna a cargo de Miguel Gimeno, 1911, pp. 61-66.

6. García Miralles, M., «La personalidad de Gil Sánchez Muñoz y la solución del Cisma de Occidente», en Teruel, 12 (1954), pp. 63-122. 
turolense transcribía tres breves documentos inéditos sobre nuestro personaje que había hallado casualmente en el Archivo Histórico de Teruel ${ }^{7}$. Sin embargo, desde 1976 hasta 2006 no ha habido más estudios monográficos. Por eso en el presente artículo nos planteamos dos objetivos simultáneos. Primero, queremos establecer un balance actual de conocimientos sobre la biografía de Gil Sánchez Muñoz contextualizada siempre dentro de la trayectoria social de su familia. Y segundo, vamos a ofrecer nueva documentación inédita encontrada tanto en el Archivo Familiar de los Sánchez Muñoz ${ }^{8}$, depositado en el Archivo Histórico Provincial de Teruel, como entre los fondos del antiguo Capítulo General Eclesiástico $^{9}$ que se conserva en el Archivo Diocesano de Teruel.

\section{CUANDO SE NACE ENTRE PRIVILEGIADOS (TERUEL 1370)}

El lugar y la fecha de nacimiento de Clemente VIII es posible conocerlos por unas notas anónimas del siglo Xv que se conservan en el archivo familiar y que dicen así: murio en Mallorqua miercoles a XXVIII de deziembre dia de los Innocentes del anyo MCCCCXXXXVII de edat de $L X X V I I^{10}$. Sobre el autor de este documento tenemos una prueba de su identidad cuando escribe en primera persona que Clemente VIII instituyó un beneficio del qual soy yo patron en la capilla de Santa Ana en la catedral de Valencia. El autor de las notas parece ser, por tanto, otro Gil Sánchez Muñoz, el sobrino del antipapa que tenía su mismo nombre, y que en 1454 dotó el beneficio que su tío instituyó sin dotación en $1405^{11}$. La información que da se confirma en las inscripciones del sepulcro de nuestro Gil en la catedral de Mallorca donde figura además como natural de Teruel (Turolii genitus) fallecido dicho año (obiit an. MCCCCXXXXVII $)^{12}$. El contexto histórico de partida es, por tanto, la ciudad de Teruel en 1370.

7. De La Vega y De Luque, C. L., «Tres documentos inéditos sobre Gil Sánchez Muñoz», en Teruel, 55-56 (1976), pp. 51-57.

8. Serrano González, R., Archivo Histórico Provincial de Teruel, Zaragoza, Gobierno de Aragón, 1995, pp. 101-102. Una parte del archivo familiar de los Sánchez Muñoz se encuentra en el Archivo de la Corona de Aragón dentro de la Sección Diversos Varia en el fondo de Babra, y otra se conserva en la Biblioteca de Cataluña.

9. López Polo, A., Catálogo del Archivo del Capítulo General Eclesiástico, Teruel, Instituto de Estudios Turolenses, 1965.

10. Archivo Histórico Provincial de Teruel, Archivo de la Familia Sánchez Muñoz, doc. 97.

11. Sobre la institución de dicho beneficio en la capilla de Santa Ana véase García Miralles, M., «La personalidad de Gil Sánchez Muñoz...», citado, p. 76.

12. La fotografía del sepulcro ubicado en la antesala capitular de la catedral de Palma de Mallorca y la reproducción de las inscripciones sepulcrales en Ibídem, pp. 101-103 y lámina 5. Véase también la reproducción de dichas inscripciones sepulcrales que hizo con anterioridad el BARÓN DE LA LINDE, Noticia históricogenealógica..., citado, pp. 63-64. 
Cuentan las crónicas de los jueces de Teruel que aquel año hubo grandes nieves y muy grandes hielos, y que se mandó quemar una cuba de vino foráneo porque estaba prohibido importarlo. Por esas fechas era juez un tío segundo de Gil, de nombre Juan Sánchez Muñoz y López de Concud, señor de Escriche difunto en $1375^{13}$. Si la población de Teruel en 1342-1343 había alcanzado un máximo histórico para toda la Edad Media con 1.525 contribuyentes del morabetí, sin embargo la recaudación del mismo impuesto en 1385 sólo presentaba 930 contribuyentes, de los cuales 66 estaban exentos de pagar por ser caballeros villanos como el padre de Gil. En hipótesis, cada uno de esos contribuyentes pudo ser el cabeza de familia de un hogar con cuatro miembros de media como mínimo. Estaríamos hablando por tanto de una cifra de población del año 1385 en torno a los 3.700 habitantes cristianos, aparte de las pequeñas comunidades de judíos y mudéjares que había en la ciudad. Obsérvese que, cinco o seis años antes de la peste negra de 1348, Teruel llegó a tener más de 6.000 habitantes con esos 1.525 contribuyentes del morabetí de 1342-1343. En 1370 el número de vecindario no debía ser tan alto. Tras el impacto de la peste debía estar más próximo a la cifra de $1385^{14}$.

La casa donde Gil vino al mundo en ese contexto pudo ser obviamente el palacio familiar de los Sánchez Muñoz, ubicado todavía hoy en la plaza de San Juan. De este edificio conocemos un inventario del año 1484, más de un siglo después del nacimiento de nuestro personaje ${ }^{15}$. Estancia por estancia se describen la entrada, un salón grande, el corral, otra sala donde dormían los mozos, la bodegueta, la habitación de un esclavo, los graneros, la cocina y su repostico, la recocina, la cámara donde dormían los señores de la casa, la habitación de las mozas, la sala mayor y su capilla, la cámara mayor de dicha sala y otros espacios, además de diversas piezas de plata, oro y joyas. Incluso el notario apuntó los bienes raíces de los Sánchez Muñoz en Teruel en 1484, indicando su situación exacta, las rentas anuales y cuándo y a quiénes se debían pagar: siete casas con sus corrales, huertos y bodegas - una casa con horno-, el molino llamado del «Cubo», varios huertos, y múltiples piezas de tierra y eras, con un total de 300 sueldos censales anuales pagaderos a Santa María, al prior del clero de Teruel y a San Andrés.

13. López Rajadel, F., Crónicas de los jueces de Teruel (1176-1532), Teruel, Instituto de Estudios Turolenses, 1994, pp. 188-192

14. Sesma Muñoz, J. A., «La población aragonesa ante la crisis demográfica del siglo XIV. El caso de la comunidad de Teruel (1342-1385)», en Estudios de Historia Medieval. Homenaje a Luis Suárez, Universidad de Valladolid, 1992, pp. 457-471. Véase también la más reciente actualización de este tema en NAVARRO Espinach, G., «Sociedad y economía bajomedievales» en Historia de Teruel, Teruel, Instituto de Estudios Turolenses, en prensa.

15. Wittlin, C. J., «Un inventario turolense de 1484: los Sánchez Muñoz, herederos de Clemente VIII», en Teruel, 51 (1974), pp. 59-82. 
Gil era el hijo primogénito del matrimonio formado por el caballero turolense Pedro Sánchez Muñoz y Liñán con Catalina Sánchez de Carbón, del que nacieron otros cuatro hermanos, de nombre Pedro, Alfonso, Catalina y Francisca. Su familia procedía de uno de los linajes más importantes de la nobleza urbana de Teruel que venía ostentando desde el siglo XIII la posesión de la baronía de Escriche. Durante los siglos XI y XII los caballeros de esta familia habían servido indistintamente a los reyes de Aragón y Castilla, al tener sus tierras en la frontera entre ambos reinos y, posteriormente, sus descendientes se asentaron en Teruel desde la conquista.

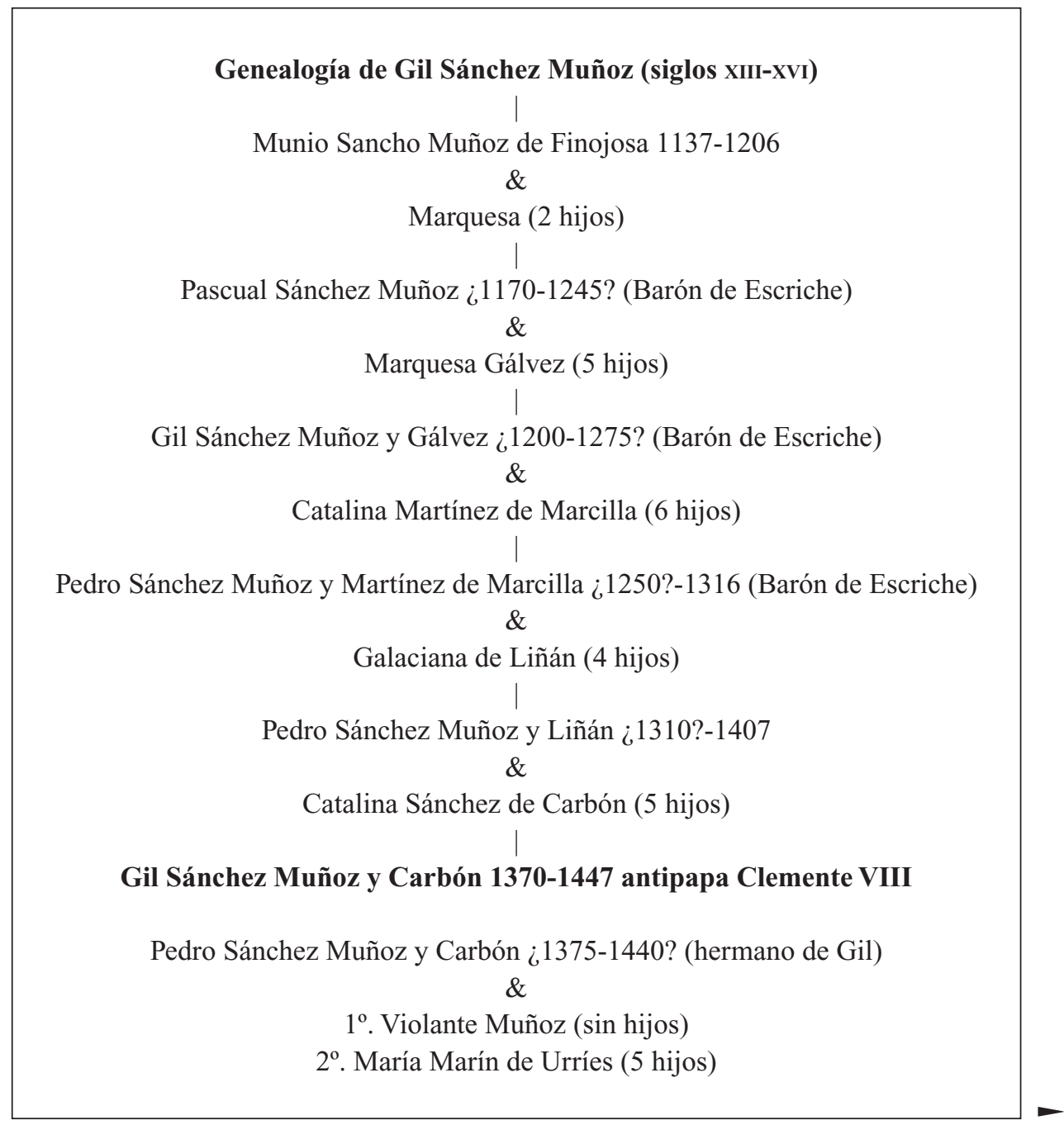


Pedro Sánchez Muñoz y Marín de Urríes 1430-1483

$\&$

Catalina Sánchez Gamir (+1517) (1 hijo)

Gaspar Juan Sánchez Muñoz y Gamir 1483-1545 (Barón de Escriche desde 1538)

$\&$

$1^{\circ}$. Ana Pérez Arnal (2 hijos)

$2^{\circ}$. Violante Malo (9 hijos)

Sin embargo, tanto el padre de Gil como él mismo no pudieron disfrutar del señorío de Escriche porque en esos tiempos ya había pasado a manos de otra rama de la familia, llegando a estar por enlace matrimonial en poder del linaje enemigo de los Marcilla. Sólo desde el año 1538, los Sánchez Muñoz les fue posible recuperarlo en la persona de Gaspar Juan Sánchez Muñoz y Gamir.

\section{Titulares de la baronía de Escriche \\ Fuera de la rama principal de los Sánchez Muñoz (1316-1538)}

Pedro Sánchez Muñoz y Martínez de Marcilla (+1316)

(último barón de la rama principal)

García Rodrigo de Urrea

Lope de Concud (1328)

Elvira López de Concud \& Juan Sánchez Muñoz y Liñán (+1346) (7 hijos)

Gil, hijo de los anteriores (sin hijos)

Juan, hermano del anterior $(+1375)$

Francisca, hermana del anterior \& Miguel Pérez del Roy (3 hijos)

Francisco Pérez del Roy, hijo de los anteriores \& Ana Gil Bardos (1 hijo) 
Elvira Pérez del Roy, hermana del anterior \& García Martínez de Marcilla (3 hijos)

Miguel Martínez de Marcilla, hijo de los anteriores (+1446) \& Catalina de Funes (5 hijos)

Francisco, hijo de los anteriores (+1474) \& Margarita Placencia (1 hijo)

Francisco, hijo de los anteriores (+1480) \& María Díaz de Molina (sin hijos)

García Martínez de Marcilla, tío paterno del anterior (+1525) \& Violante Cubells

Gaspar Juan Sánchez Muñoz y Gamir

(recupera la baronía para la rama principal desde 1538)

\section{LA CARRERA ECLESIÁSTICA Y EL DOCTORADO EN DECRETOS}

Gil, primogénito de sus padres, no sabemos por qué motivos optó por la carrera eclesiástica en vez de las armas que hubiese sido lo lógico en una familia como la suya en aquella época. Tal vez lo hizo por influencia de su tío Gil Sánchez Muñoz y Liñán, pavorde de Valencia, fallecido en 1388 cuando el sobrino sólo tenía 18 años. De hecho, según un memorial realizado para el procurador real de Mallorca -documento hasta hoy inédito (véase apéndice documental $\mathrm{n}^{\mathrm{o}}$ 1)-, nuestro Gil heredó de su tío diversos objetos personales y una renta de más de tres mil florines de Aragón como cobrador de la cámara apostólica de Aviñón. En esas circunstancias, el destino de nuestro personaje derivó por la carrera eclesiástica, lo que en aquellos instantes debió parecer la ruta más prometedora para este primogénito a falta de la principal posesión del linaje, la baronía de Escriche. Y como debiera haber sido caballero y no lo fue, a veces en la documentación suele asignársele el apodo de «Doncel». Al respecto, el memorial antes citado explica que en el momento de ser elevado al pontificado estaba en dicho estamento y mantenía cuatro o cinco cabalgaduras.

Sobre su educación hay muy pocas noticias por ahora. La referencia más clara corresponde a 1396, cuando ya había cumplido los veinticinco años y se le identifica como «bachiller en decretos» ${ }^{16}$. Debió aprender sus primeras letras

16. García Miralles, M., «La personalidad de Gil Sánchez Muñoz...», citado, p. 69. 
de la mano de algún preceptor doméstico en el palacio de su familia en Teruel o bien directamente en la escuela de gramática de la catedral de Valencia. El proceso de formación del clero secular se iniciaba con la etapa de estudiante, la cual se correspondia en líneas generales con el grado de tonsurado. El inicio de esta enseñanza iría destinado a dotarlo de las nociones básicas de lectura y escritura latina, así como la aritmética precisa para el desarrollo de la liturgia y el establecimiento del calendario eclesiástico ${ }^{17}$.

Hacia los quince años de edad empezaría los estudios de leyes que, tras cuatro o cinco cursos, le permitirían alcanzar el citado grado de bachiller. Parece confirmarse también su formación universitaria, puesto que en 1429 se le califica como «doctor en decretos» ${ }^{18}$. Siguiendo el esquema de estudios propio de aquella época, eso significa que, tras conseguir el grado de bachiller, cursó otros tres años más hasta convertirse en «maestro» o licenciado, alcanzando tal vez paralelamente el presbiterado. Posteriormente, ingresaría en una facultad de Teología con vistas a especializarse en derecho canónico con el estudio preferente de las decretales pontificias, de manera que siete u ocho años después culminaría su carrera mediante la obtención del título de doctor. Quizás siguiese el modelo de su compatriota aragonés y antecesor suyo, el papa Benedicto XIII, quien se formó en la carrera de leyes en Montpellier, una universidad que junto con las de Aviñón y Toulouse era de las más frecuentadas por los estudiantes aragoneses del siglo XIV, no sólo por hallarse en las tierras más próximas del sur de Francia, sino especialmente por la presencia de la misma curia papal en Aviñón desde que en 1309 se trasladó allí abandonando Roma ${ }^{19}$.

Las noticias sobre los cargos eclesiásticos que desempeñó nuestro personaje también se inician en 1396, cuando el citado Benedicto XIII, el papa Luna, le concedió la chantría de la catedral de Gerona, dignidad cuya misión era la de dirigir las actividades del coro y organizar la ejecución del canto litúrgico. Por esas fechas pues ya habría sido ordenado presbítero. En 1400 aparece por primera vez como canónigo de la catedral de Valencia y en 1402 recibe un nuevo beneficio como rector de la iglesia de Onteniente. El nombramiento de nuestro Gil como vicario general de la diócesis valenciana se produce al poco tiempo, en el año

17. Sobre las etapas de formación del clero secular véase Munsuri Rosado, M. N., Perspectiva socio-económica del clero secular en la Valencia del siglo XV, Tesis Doctoral inédita, 2 vols., Universidad de Valencia, curso 2005-2006, dirigida por P. Iradiel Murugarren, en concreto tomo I, pp. 353 y siguientes.

18. García Miralles, M., «La personalidad de Gil Sánchez Muñoz...», citado, p. 71

19. Benedicto XIII. La vida y el tiempo del papa Luna, Zaragoza, Caja de Ahorros de la Inmaculada de Aragón, 1987, pp. 27-28. Véase también los textos de diversos autores en el catálogo de la exposición Benedicto XIII, el Papa Luna, Muestra de Documentación Histórica Aragonesa en conmemoración del Sexto Centenario de la Elección Papal de Don Pedro Martínez de Luna (Aviñón, 28 septiembre 1394), Zaragoza, Gobierno de Aragón, 1994. 
1408. Tres años antes, en 1405 instituyó un beneficio que no dotó finalmente en una capilla dedicada a Santa Ana en la misma catedral de Valencia. La capilla, llamada de los «Muñoces», había sido fundada años antes por su tío Gil que también fue canónigo en dicha sede. La dotación final del beneficio corrió a cargo en 1454 de otro descendiente, su sobrino Gil, posible autor de aquellas notas que citábamos al principio. La acumulación de cargos eclesiásticos en nuestro personaje se extendió además con los de cura párroco de Sueca y Cullera, el arciprestazgo de Santa María de Teruel o el beneficio patrimonial de la iglesia parroquial de San Martín de esta última ciudad. A través de la documentación del archivo de la catedral de Valencia se sabe que residía habitualmente en esta ciudad ${ }^{20}$.

Un memorial para el procurador real de Mallorca, primer documento publicado en nuestro apéndice, confirma que, antes de ser promovido como papa en Peñíscola, Gil era canónigo de Valencia, chantre de Gerona y arcipreste de Teruel, aparte de tener bienes patrimoniales en esta última ciudad y recibir cierta pensión censal de la ciudad de Albarracín. Dichos bienes patrimoniales de Teruel antes de ser papa consistían en arreos de casa, vestiduras, libros de teología y derecho canónico, una vajilla de plata y cálices, todos ellos por herencia de sus padres o de su tío paterno, del cual había percibido también su renta como cobrador de la cámara apostólica.

\section{EL PONTIFICADO EN PEÑÍSCOLA HASTA SU RENUNCIA (1423-1429)}

La culminación de su promoción eclesiástica al pontificado en los años finales del gran cisma de la iglesia de Occidente (1378-1423) se puede entender en primer lugar por el grado de amistad y relación que pudo tener con sus antecesores Clemente VII y Benedicto XIII en Aviñón y Peñíscola, así como por el interés político del rey Alfonso $\mathrm{V}$ el Magnánimo en mantener un pontífice aragonés a su lado frente a la influencia de Francia sobre Martín V. Incluso parece que Gil acompañó ya en 1405 al papa Luna cuando éste encabezó una escuadra naval contra el recién electo papa Inocencio VII. Lo cierto es que el 10 de junio de 1423 fue elegido papa en el castillo de Peñíscola por un cónclave compuesto únicamente por tres cardenales de los cuatro que nombró en vida su antecesor el papa Luna, es decir, Dominique Bonnefoi, Jimeno Doha y Julián de Loba. El cuarto cardenal, Jean Carrier, no estuvo presente en la elección de nuestro personaje -tildándola de simoniaca- y creyéndose como el único con derecho a voto, acabó eligiendo en 1425 a Bernard Garnier, sacristán de Rodez, como verdadero sucesor del papa Luna con el nombre de Benedicto XIV. Incluso, un

20. Sobre sus cargos eclesiásticos véase García Miralles, M., «La personalidad de Gil Sánchez Muñoz...», citado. 
nuevo cardenal creado por Garnier, eligiría después al mismísimo Jean Carrier como papa, quien paradójicamente tomó el mismo nombre de Benedicto XIV que había ostentado su predecesor.

El concilio de Constanza de 1414 ya había supuesto la confirmación de Martín $\mathrm{V}$ como único pontífice de la iglesia católica, tras el sometimiento del antipapa Juan XXIII, la abdicación de Gregorio XII y la deposición del propio papa Luna. A la muerte de este último en 1423, la reina María, esposa de Alfonso V el Magnánimo, no dudó en mandar al gobernador de Castellón para que las tropas reales se apoderaran por la fuerza de la sede de Peñíscola y sus moradores cismáticos. Sin embargo, el rey Alfonso V de vuelta a Aragón revocó las disposiciones de su esposa regente y en 1424 ordenó al baile general del reino de Valencia que entregara a Clemente VIII una cantidad anual de 16.000 florines de oro para su mantenimiento y supervivencia en respuesta a la excomunión dictada contra él por Martín $\mathrm{V}^{21}$.

En efecto, el memorial que reproducimos en nuestro apéndice cuenta que Gil estuvo en Peñíscola durante siete u ocho años durante los cuales hizo gastos y solicitó diversos créditos para la manutención del castillo papal. El texto citado reconoce que el rey Alfonso V el Magnánimo le concedió para su sustento la cantidad de 16.000 florines anuales, sin embargo, durante todos esos años que estuvo en Peñíscola sólo percibió en total 7.000 florines, hasta el punto de que, para sobrevivir, empeñó un diamante. En un principio esta piedra preciosa había sido depositada en la ciudad de Valencia a cambio de 4.000 florines, pero el propio Gil la recuperó para volver a empeñarla por una cantidad de dinero más alta, esta vez por 6.000 florines a un tal Bernat Jornet, siempre para la sustentación del castillo de Peñíscola.

Quizá por ese apoyo tardío del rey de Aragón se comprenda que no fue hasta el 19 de mayo de 1426, tres años después de su elección, cuando Clemente realizó el acto solemne de su autocoronación en el castillo de Peñíscola. Ante estas circunstancias, Martín V envió al cardenal de Foix en condición de legado papal ante el rey para suprimir las diferencias que mediaban entre ellos y zanjar el problema de manera definitiva. En el mes de mayo de 1429 el rey envió varios embajadores a Clemente, entre ellos Alfonso de Borja (futuro Calixto III), los cuales consiguieron que el 26 de julio de ese mismo año Gil Sánchez Muñoz renunciase a su dignidad, tras varios años de mandato desde su elección en 1423.

¿Qué sucedió en el momento de la renuncia? Nuestro memorial reproducido en el apéndice explica que el papa Martín $\mathrm{V}$ quiso que se indemnizara por valor de 4.000 florines de oro a Gil en compensación por los bienes de su propiedad

21. Sobre todos estos documentos consúltese Ibidem. 
que estaban en el castillo de Peñíscola y que habían sido confiscados. Además, cuando Gil salió de Peñíscola ya sin la dignidad pontifical fue a Valencia para seguir disfrutando de las rentas de sus cargos eclesiásticos con el beneplácito del rey de Aragón y del papa. Allí estuvo varios meses poco más o menos, es decir, desde agosto a octubre de 1429 , fecha esta última en que tomó posesión del obispado de Mallorca.

\section{EL OBISPADO DE MALLORCA HASTA SU MUERTE (1430-1447)}

$\mathrm{Y}$ es que, enterado del sometimiento voluntario de Clemente VIII a la renuncia, Martín V le nombró obispo de Mallorca. Con una bula fechada el 19 de octubre de 1430 ordenó prestarle obediencia como tal, a la vista de que se había dotado dicha sede a favor de otra persona por petición del rey, desconocedor éste de la gracia concedida a Gil Sánchez Muñoz por su adversario. Hasta su muerte el 28 de diciembre de 1447 desempeñó dicha dignidad. En la antesala capitular de la catedral de Palma de Mallorca puede visitarse su sepulcro. El memorial que reproducimos en el apéndice explica que Gil llegó a la ciudad de Mallorca con sus bienes y rentas particulares, separadas de las del obispado, y que en vida las donó a sus parientes, concretamente a su sobrino mayor Pedro Sánchez Muñoz y Marín de Urríes (1430-1483).

El memorial en cuestión indica claramente que Gil murió sin testamento u otra última voluntad y que su herencia pasó a sus sobrinos como personas más cercanas en parentesco por sucesión intestada. Las notas anónimas elaboradas posiblemente por uno de esos sobrinos que hemos citado al principio dicen, sin embargo, que recibio el testamento del obispo de Mallorqua don Gil Sanchez Munyoz Ludovici Ferrarii vel Ferracii notario de Valencia a XX de setiembre de MCCC X, tiene estas notas Jacobum de Monteforti notario de Valencia ${ }^{22}$. En ningún archivo valenciano ni siquiera en el de la Catedral de Valencia hemos podido localizar dicho testamento.

En el Archivo Diocesano de Teruel hay un documento en que se recoge un listado de las reliquias que el antipapa Clemente VIII halló en la tumba del papa Luna en Peñíscola y que el poseyó después hasta su propia muerte en Mallorca. Luego las reliquias pasaron a poder de su sobrino y también clérigo Dionisio Sánchez Muñoz que en vida las donó a la iglesia parroquial de San Pedro en la ciudad de Teruel. Es el segundo documento que reproducimos en nuestro apéndice documental y viene a confirmar que tanto el papa Luna como Clemente VIII seguían poseyendo siempre junto a sí la fusta de la Vera Cruz y otras reliquias relacionadas directamente con la Pasión de Cristo: el pilar en el qual Nuestro

22. Archivo Histórico Provincial de Teruel, Archivo de la Familia Sánchez Muñoz, doc. 97. 
Sennor fue açotado, la fusta de la lança de Longinos, el arca de los Santissimos Corporales, y hasta la tierra del Sancto Sepulcro ${ }^{23}$.

Recientemente, Nieves Munsuri ha recogido datos concretos sobre el citado sobrino Dionisio, heredero de las reliquias de Clemente VIII, en su estudio prosopográfico sobre el clero secular en la Valencia del siglo XV. La autora anota que fue presbítero en la ciudad de Valencia, donde declaró en 1448 que poseía una casa en la parroquia de San Salvador, constando asimismo como canónigo de la catedral de Mallorca. El hermano mayor de Dionisio y, asimismo, sobrino de Clemente VIII, citado antes aquí como patrón de la capilla de Santa Ana, se llamaba también Gil Sánchez Muñoz, y fue canónigo de la catedral de Valencia, archidiácono de Sagunto, protonotario del papa y receptor de diversos beneficios eclesiásticos hasta su muerte en $1471^{24}$. Nuestra investigación sigue en marcha y por ahora merece la pena dar a conocer estos dos documentos importantes sobre el antipapa Clemente VIII, teniendo en cuenta que no son definitivos ni agotan las vías de análisis que tenemos previstas para el futuro.

\section{APÉNDICE DOCUMENTAL}

\section{(1)}

Sin fecha ni lugar de redacción (escrito quizás en Palma de Mallorca en 1448, el año siguiente al de la muerte de Gil Sánchez Muñoz).

Memorial de los bienes del difunto Gil Sánchez Muñoz, obispo de Mallorca, realizado para conocimiento de Juan Albertí, procurador real en el reino de Mallorca, donde se especifica cuáles pertenecen a sus sobrinos en calidad de herederos y cuáles no.

Archivo Histórico Provincial de Teruel, Archivo de la Familia Sánchez Muñoz, Documento núm. 30 (dos folios).

[Folio 1r] Memorial per a lo molt honorable mossén Johan Albertí, cavaller procurador real en lo regne de Mallorques, per què sia avissat a satisfer a totes aquelles persones les quals o devant nostre sant pare o devant lo molt excel-lent lo senyor rey volrran dir e diran que los béns que lo molt reverent senyor e pare en Crist don Gil, bisbe quondam de Mallorques, havia no pertanguen als nebots del dit senyor bisbe.

23. Véase Navarro Espinach, G., «Las cofradías de la Vera Cruz y de la Sangre de Cristo en la Corona de Aragón (siglos XIV-XVI)» en Anuario de Estudios Medievales, 36/2 (2006), en prensa.

24. Las prosopografías de los hermanos Gil y Dionisio Sánchez Muñoz en Munsuri Rosado, M. N., Perspectiva socio-económica del clero secular en la Valencia del siglo $X V$, tesis doctoral citada, tomo I, pp. 767-769 y 823 respectivamente. 
Primerament, sia avisat que lo dit senyor bisbe ans que fos promogut en la pontifical dignitat en Peníscola era canonge de València e cabiscol de Gerona e arciprestre de Terol, los fruyts dels quals beneficis fahia sens e no res menys tenia béns patrimonials en la ciutat de Terol e prenia cert censsal en la ciutat d'Albarrazí.

Item lo dit senyor bisbe tenia ans que hagués la dita pontiffical dignitat béns mobles axi en arreus de casa com vestidures, com argent, e libres axí de teologia com de dret canònich, calcers axí atquisits per aquell com per successió del reverent micer Gil, oncle paternal seu, com per successió de son pare e mare, e fonch vist lo dit senyor bisbe tenir vexella d'argent, ço és, dotze plats e dotze scudelles, pichers, copes, taces, plats per lavar mans e altre argent.

Item lo dit senyor bisbe stava bé en cavalgar segons sos stament de quatre o cinch cavalgadures e en stant en aquest stament fonch promogut a la dita dignitat en Peníscola.

Item lo dit senyor bisbe stech en Peníscola per set o VIII anys, e aprés se seguí concòrdia e unió de la iglèsia e en aquella concòrdia entervengueren certs capitols los quals foren fermats entre los ambaxadors del dit molt excel-lent lo senyor rey e lo dit senyor bisbe los quals capitols són en un altre trellat.

Item en los dits capitols pot ésser vist que lo dit senyor bisbe per successió del dit reverent micer Gil Sànchez Munyoç era cobrador de la cambra apostolical en tres milia trescents tres florins d'Aragó e hun gros de moneda d'Avinyó.

Item en los dits capitols pot ésser vist ço que despés lo dit senyor bisbe en lo temps que stech en Peníscola e los crèdits que causà, e les quals despeses e crèdits li foren admesses en la firma dels dits capitols.

[Folio 1v] Item per los dits capitols appar que los béns que eren en lo castell de Peníscola devien romandre al dit senyor bisbe, exceptats alguns o si aquells béns volia lo dit senyor rey a donar per aquells quatre milia florins d'or.

Item appar per actes e senyaladament per hun breu del sant pare papa Martí endreçat al molt reverent cardenal de Foix que lo dit sant pare volia que les coses concordades ab lo senyor bisbe se exseguissen e senyaladament volia que los béns de Peníscola, los quals lo dit cardenal se'n havia portats, li foren restituits o per aquells béns quatre milia florins; del dit breu hi ha trellat lo qual davall és continuat.

Item semblant breu hi ha nostre sant pare papa Eugeni dictat al dit cardenal de Foix; d'aquest breu hi ha així mateix trellat davall continuat.

Item lo dit senyor bisbe hixqué de Peníscola solament bisbe en la iglésia universal sens dignitat alguna que no havia e sti vench a València tenint sos bennifficis, los quals dessús són specifficats, e tenint béns axí argent com robes e libres, e altres joyes, los quals eren seus propris axí aquisits de patrimoni que als feyts 
sens com encara per la concòrdia dessús dita feyta de volentat, consentiment e beneplàcit del dit nostre sant pare papa Martí, com encara del dit senyor rey.

Item lo dit senyor bisbe aprés hac la iglésia de Mallorques e vench en la dita ciutat portant ab si tots los béns dessús senyaladament nomenats, los quals béns no eren atquisits de les rendes de la dita iglèsia de Mallorques ans segons és dit eren propris del dit senyor bisbe e separats de la dita sglésia de Mallorques.

Item lo dit senyor bisbe, morint sens testament o altra derrera voluntat, és clar en via de dret que tots los béns atquisits per aquell ans que fos bisbe de Mallorques han pertangut e pertanyen als nebots seus e fills de sos germans axí com a persones pus proprinques a aquell e aço per successió ab intestat.

[Folio 2r] Item lo dit senyor bisbe podia de dret en vida sua donar de sos béns hoc encara atquisits del bisbat, e aço a sos parents segons que ha fet a Pero Sànchez Munyoç, nebot seu fill de Pero Sànchez Munyoç, germà del dit senyor bisbe, appar de la dita donació ab carta pública de la qual hi ha trellat.

Item en quant se faça menció de hun diamà se pot dir ab justícia que lo dit senyor bisbe se posgué recebir aquell en vigor dels dits capitols e concòrdia maiorment com en lo temps que ell vench a Paníscola stava penyora per quatre milia florins en la ciutat de València en poder de singulars persones e fonch quitat per lo dit senyor e après empenyorat per sis milia florins a micer Bernat Jornet, e aço per obs de sustentació en lo dit castell de Peníscola.

Item lo dit molt excel-lent lo senyor rey offerí donar al dit senyor bisbe per tot lo temps que stigués en Peníscola per sustentació sua XVI milia florins tots anys segons appar per albarà scrit de ma de mossén Francisco de Arinyo e sots signat de ma del dit molt excel-lent lo senyor rey, dels quals lo dit senyor bisbe per tot lo temps que stech en lo dit castell no hac sino set milia florins.

Sin lugar ni fecha de redacción (realizado después de la muerte de Dionisio Sánchez Muñoz en la segunda mitad del siglo Xv).

Inventario de las reliquias que regaló el difunto Dionisio Sánchez Muñoz a la iglesia parroquial de San Pedro de Teruel y que él a su vez había recibido de su difunto tío Gil Sánchez Muñoz, obispo de Mallorca, quien las halló entre los restos del papa Benedicto XIII en el castillo de Peñíscola.

Archivo Diocesano de Teruel, Capítulo General Eclesiástico, Pergaminos, núm. 294.

$+$

Las siguientes reliquias dio mossen Dionis Sançhez Munyoz quondam a la iglesia de Sant Pedro las quales uvo del Reverendo Senyor don Gil Sançhez Munyoz quondam obispo de Mallorca el qual siendo electo en el castillo de Pe- 
niscola en sucçesor de papa Bendito hallo las infrascriptas reliquias en el despojo del sudito sancto padre:

Primo de la fusta de la Vera Cruz

Item de la leçe de la Virgen Maria

Item de la ropa de la Virgen Maria

Item del pilar en el qual Nuestro Sennor fue açotado

Item de los huessos de Sant Pedro y Sant Pablo apostoles

Item [tachado: un quixar] una muela de Sant Pedro apostol

Item [tachado: un quixar] una muela de Sant Clemente y hun huesso

Item de la mirra que presentaron los tres reyes

Item de la [tachado: verga] vara de Moyses

Item de la mano de un Innocente

Item un huesso de Sant Christoval

Item un huesso de Sant Valentin martir

Item de los huessos de Sant Pedro Alexandrino papa y martir

Item de los huessos de Sant Lino papa y martir sucçesor de Sant Pedro

Item un huesso de Sant Hilario de Pictavia

Item de los huessos de Sant Andres

Item de los huessos de Sant Estevan

Item de los huessos de Sant Llorençe

Item de los huessos de Sant Viçente

Item del abito de Sant Françisco

Item de la fusta de la lança de Longinos

Item del velo de Sancta Clara

Item de los huessos de Sant Nicolas

Item de los huessos de Sancto Domingo

Item de los huessos de Sancta Catalina

Item de los huessos de Sant Tomas de Contuberi

Item de los huessos de Sant Jorge

Item de los huessos de Sant Bartholome apostol

Item de los huessos de Sant Cosme y Damian

Item del arca de los Santissimos Corporales

Item de los huessos de Sant Tomas apostol

Item de los huessos et carne de Sant Blas

Item de los huessos de Sant Sebastian ay una costilla y de la sangre

Item de los huessos de Sancta Engraçia martir es de Çaragoça

Item de los huessos de Sancta Margarita

Item una costilla de Sancta Agueda

Item del sepulcro de Sancta Anna madre de la Virgen Maria 
Item de los huessos et sangre de las onze mil virgines

Item de los huessos de Sancta Luçia

Item de las piedras del sepulcro de Santa Susanna

Item un huesso de Sant Valero

Item de las cruzes de Sant Pedro y Sant Andres

Item de los huessos de Sant Juan y Sant Pablo martires

Item de la tierra del Sancto Sepulcro

Et muchas infinitas otras reliquias que no estan puestas en el presente memorial las quales estan en el presente relicario. 